This item was submitted to Loughborough's Research Repository by the author.

Items in Figshare are protected by copyright, with all rights reserved, unless otherwise indicated.

\title{
New statistical methods for the comparison and characterisation of particle shape
}

PLEASE CITE THE PUBLISHED VERSION

https://doi.org/10.1002/esp.4669

\section{PUBLISHER}

(c) Wiley

\section{VERSION}

AM (Accepted Manuscript)

\section{PUBLISHER STATEMENT}

This is the peer reviewed version of the following article: GRAHAM, D.J. and GADSDEN, R.J., 2019. New statistical methods for the comparison and characterisation of particle shape. Earth Surface Processes and Landforms, 44 (12), pp.2396-2407, which has been published in final form at https://doi.org/10.1002/esp.4669. This article may be used for non-commercial purposes in accordance with Wiley Terms and Conditions for Use of Self-Archived Versions.

\section{LICENCE}

CC BY-NC-ND 4.0

\section{REPOSITORY RECORD}

Graham, David, and Richard J. Gadsden. 2019. "New Statistical Methods for the Comparison and Characterisation of Particle Shape". Loughborough University. https://hdl.handle.net/2134/37793. 
New statistical methods for the comparison and characterisation of particle shape

DAVID J. GRAHAM* and RICHARD J. GADSDEN ${ }^{\dagger}$

*Geography and Environment, Loughborough University, Loughborough, Leicestershire LE11 3TU, UK (E-mail: D.J.Graham@Iboro.ac.uk)

${ }^{\dagger}$ Formerly: Mathematics Education Centre, Loughborough University, Loughborough, Leicestershire LE11 3TU, UK

Corresponding author: David Graham 


\section{ABSTRACT}

This paper presents novel methods for robust statistical testing of particle shape data. Shape (the relative lengths of three orthogonal axes) is a key property of sedimentary particles, providing information on provenance, transport history and depositional environment. However, the usefulness of shape data, including the ability to make robust comparisons between samples, has been constrained by the absence of a satisfactory definition of the mean shape for a sample of particles. Such a definition is proposed and used to develop confidence regions for the population mean shape using both parametric (theoretical) and computational (bootstrap) methods. These techniques are based on a transform that permits multivariate statistical methods for the analysis of compositional data to be extended to shape. These techniques are validated with reference to a dataset of 169 clast samples and found to perform well. A statistical test on the mean - using the multivariate extension of Student's $t$-test, Hotelling's $T^{2}-$ is presented. The benefits of the methods presented are demonstrated with reference to a case study.

Keywords Ternary diagram, Sneed and Folk diagram, Zingg diagram, particle shape, clast morphological analysis. 


\section{INTRODUCTION}

The morphology or form of sedimentary particles is related to their shape (the relative lengths of the three orthogonal axes), roundness (the smoothness or angularity of the edges) and surface texture (roughness and surface markings) (terminology after Benn and Ballantyne, 1993). Each of these properties is modified in a variety of ways by different sediment transport processes. Individually or in combination, these properties can be used to differentiate sedimentary facies, provide evidence about the transport history of the sediment, and characterise the depositional environment (Evans and Benn, 2004). Particle-form analysis thus provides valuable information to aid the interpretation of sediment bodies.

In most disciplines, samples are compared on the basis of standard descriptive statistics, the most basic of which measure central tendency and spread. In sedimentology, the usefulness of particle-shape analysis as a diagnostic indicator of process domain or to distinguish between sedimentary facies has been inhibited by the absence of an accepted method of determining typical or 'average' shapes. This has precluded robust, quantitative testing of differences between populations (where we use the term 'robust' to mean that it works well, even when data are skewed or contain outliers). Even differentiating samples visually is difficult because populations associated with very different process domains commonly have substantial overlap in particle shape when plotted on conventional diagrams (e.g. Dowdeswell et al., 1985; Bennett et al., 1997). 
The difficulty in defining 'average' particle shape results from the inherent three-dimensional nature of shape, and disagreements over the most effective way of representing it. The development of such a method is highly desirable because it facilitates the application of inferential statistics to shape data, and consequently enables robust comparisons between samples. This paper explores alternative ways of representing particle shape, identifies the difficulties of determining the 'average' shape within a sample, and presents solutions to the problem of defining confidence regions for the 'average' shape within the population. On the basis of these solutions, statistical tests on the mean are presented. The methods are validated with reference to a dataset consisting of 169 samples, each of 50 clasts, collected from a variety of facies within glaciated and glacierized environments. This paper is the first published statistical treatment of three-dimensional sedimentary particle shape and represents a substantial enhancement to the toolkit available for the analysis of sediments.

\section{REPRESENTING PARTICLE SHAPE}

The shape of a sedimentary particle is defined by the relative lengths of its three orthogonal axes, conventionally labelled $a$ (or long, $L$ ), $b$ (or intermediate, $I$ ) and $c$ (or short, S) (Benn and Ballantyne, 1993). By definition, $a \geq b \geq c$. Because shape is based on relative axis lengths (making it conceptually independent of size), it is usually characterised using axial ratios, but its trivariate nature means that it cannot be represented completely by any single index. 
A variety of ratio-based shape indices are possible (Blott and Pye, 2008), the index chosen depending on the property of particular importance for the application. For example, the degree of flattening is an important control on the propensity for fluvial transport (Oakey et al., 2005), making an index of flatness $(c / b)$ most useful in this context. Similarly, the measure of particle size obtained from a square-hole sieve (commonly used as a proxy for the $b$-axis) differs from the true $b$-axis (as measured by a ruler or callipers) as a function of particle flatness (Church et al., 1987). When settling velocity is important, maximum projection sphericity, ${ }^{3} \sqrt{ }\left(c^{2} / a . b\right)$, might be the most important index of shape (Folk, 1955; Sneed and Folk, 1958).

The use of axial ratios also makes it possible to condense the three components of shape into two indices without losing any information, making the graphical representation of the three-dimensional character of shape a more tractable problem. A variety of approaches for doing this have emerged, all of which have benefits under certain circumstances. However, two diagrams, based on different geometric conceptions of particle shape, have been widely adopted for the representation of shape data and to enable visual comparisons to be made between samples (Sneed and Folk, 1958; Zingg, 1935). Zingg (1935) conceived shape as existing in a bivariate Cartesian geometric space in which indices of flatness $(c / b)$ and elongation $(b / a)$ are plotted (Fig. 1A). In contrast, Sneed \& Folk (1958) considered particles to lie within a ternary space, the apices of which represent equant $(a=b=c)$, platy $(a=b>>c)$, and elongate $(a>>b=c)$ particles (Fig. 1B; terminology after Blott and Pye, 2008). The Sneed and Folk diagram is scaled differently from conventional compositional ternary diagrams, in which the components sum to 
unity. Both the Zingg and Sneed \& Folk diagrams can be divided into shape classes, each with descriptive names (Fig. 1). Conversion to a nominal scale by counting the number of particles within each class enables quantitative comparisons to be made between samples in a rather crude way.

The relative merits of the Zingg (1935) and Sneed \& Folk (1958) approaches are strongly contested (Benn and Ballantyne, 1992, 1993, 1995; Blott and Pye, 2008; Graham and Midgley, 2000; Hofmann, 1994, 1995; Howard, 1992, 1993; Illenberger, 1991, 1992a, 1992b; Woronow, 1992). The approaches are fundamentally different in that Zingg (1935) recognised four shape end members (representing degrees of flattening and elongation) whereas Sneed \& Folk (1958) recognised only three. In the Zingg diagram, the largest shape class represents blades $(a>>b>c)$, whereas this class is considered intermediate between platy and elongate shapes in the Sneed \& Folk diagram.

Blott \& Pye (2008) argued that the Zingg diagram best represents the shape field without distortion. They demonstrated this by simulating particles with random shapes using a computer. Random a-axis lengths were drawn from a uniform distribution. Values of $b$ were then drawn such that $0 \leq b \leq a$, followed by values of $c$ such that $0 \leq c \leq b$. This results in an even distribution when plotted on the Zingg diagram, but a concentration in the right-hand corner of the Sneed \& Folk diagram (Fig. 2A). Blott (pers. comm.) argued that for a truly random sample of grains, every value of the elongation $(b / a)$ and flatness $(c / b)$ indices should be equally probable (with the result that the sample is distributed evenly on the Zingg diagram). 
We consider this approach to be flawed because, when drawn in this way, the particle axes are not independent. Conceptually, there is no justification for drawing the a-axis first; it is equally reasonable to draw the $c$ - or $b$-axis first. However, the order in which the axes are drawn affects the distribution on the Zingg and Sneed \& Folk diagrams (Fig. 2).

We argue that a more appropriate method is to draw random triplets of numbers from a uniform distribution, and then order them such that the largest is defined as $a$, and the smallest as $c$. This better reflects the way in which the shape of particles is defined: the three axial lengths exist independently and we simply label them such that $a \geq b \geq c$. Our method results in an even distribution of points on the Sneed \& Folk diagram, but clustering towards the top of the Zingg diagram (Fig. 2D). The shape continuum becomes increasingly distorted towards the bottom of the Zingg diagram, resulting in increased resolution within the part of the diagram representing elongated forms (rods and blades) (Benn and Ballantyne, 1993; Benn, 2004; Lukas et al. 2013). In the limiting case of an extreme rod (an infinitely long and thin particle), the particle does not plot uniquely. In the Sneed \& Folk diagram, this shape is resolved as a single point (the right-hand apex), but in the Zingg diagram is stretched out along the entire $x$-axis (Fig 3).

For those applications where the distinction between rods and blades is important (e.g. Oakey, 2002; Oakey et al., 2005), the greater emphasis given to bladed particles within the Zingg diagram may be advantageous. Similarly, other geometric representations of the shape continuum may be useful in particular circumstances (e.g. in archaeology, where orientation is important: 
Tarriño, 2015). However, from a sedimentological perspective it is most useful to present particle-shape data in a form that most faithfully represents the shape continuum without distortion, and we contend that the ternary space of Sneed \& Folk is therefore more appropriate (see also Benn and Ballantyne, 1993; Graham and Midgley, 2000; Benn, 2004; Lukas et al. 2013). This ternary space forms the basis of the definition of 'average' shape developed here for a sample of particles, and the definition of confidence regions for the population which is derived from it.

\section{THE DEFINITION OF MEAN PARTICLE SHAPE}

While the use of Sneed \& Folk diagrams provides a useful means of presenting shape data, it is not easy to make comparisons between samples using the diagrams. First, because each sample is represented by a cloud of points, clarity necessitates plotting each on a separate diagram. Second, even for samples drawn from different sedimentary populations, there is typically substantial overlap between the point clouds. While it is possible to differentiate samples visually, there is no rigorous method for determining whether they come from the same, or different, populations. A first step to enabling robust comparisons between samples is the development of a method for calculating 'typical' or 'average' particle shapes.

Oakey et al. (2005) presented a potential method for determining 'average' and 'extreme' particle shapes within samples, with the aim of selecting appropriate tracer shapes for use in fluvial sediment transport studies. Their definition of median particle shape was based on the centroid of the scatter of points, an approach which seems entirely reasonable. However, although 
transformed into a polar coordinate form, the centroid was based on the distribution within the Zingg diagram (with its inherent distortion to the shape continuum), whereas the true 'average' shape should be based on the undistorted shape continuum in the Sneed \& Folk diagram.

Because the shape of a particle is defined by the ratios of its axes, the 'average shape' should be based on averages of these ratios (not on ratios of the average axis lengths). Furthermore, the appropriate 'average' to use when dealing with ratios is the geometric mean (the arithmetic mean may be highly atypical when applied to ternary data; Weltje, 2002). However, direct calculation of the geometric mean for each of the three Sneed \& Folk ratios results in a triplet that does not plot uniquely on the diagram. This is because, unlike the type of ternary diagram used to represent compositional data, the scaling of the Sneed \& Folk diagram is such that the three ratios do not sum to unity.

An alternative approach is developed here, based on a set of transformations designed to make the analysis more tractable, and building on techniques developed for the analysis of compositional data (Weltje, 2002). The objective is to transform the data in such a way that the sample mean can be calculated easily and allow the application of conventional parametric statistics to derive confidence regions for the population mean and undertake multivariate inferential statistical tests on the mean.

The first step is to transform the raw $a-, b$-, and $c$-axes data, making them equivalent to compositional data. This is necessary to remove the constraint on statistical analysis imposed by the fact that (by definition) $a \geq b \geq c$. 
Following transformation, the data plot in exactly the same locations on a conventional (compositional) ternary diagram as they do on the Sneed \& Folk shape diagram, but each of the three derived components $\left(x_{1}, x_{2}, x_{3}\right)$ can take any value within the interval $\{0<x \leq 1\}$ subject to the constraint that $x_{1}+x_{2}+$ $x_{3}=1$. Such data are amenable to analysis by methods developed for compositional data. The transformation is described in Table 1, and the identical disposition of data points in both ternary spaces is illustrated in Fig. 4 (with reference to a sample of 50 clasts from a Svalbard moraine composed of sandy gravel). To differentiate it from the Sneed \& Folk scaling, the conventional ternary diagram is referred to as $x$-space.

In $x$-space, the mean is best described by the geometric mean of the three components (Weltje, 2002). The geometric mean for dataset $\left(d_{1}, d_{2}, \ldots, d_{n}\right)$ is given by:

$\sqrt[n]{d_{1} d_{2} \cdots d_{n}}$

To plot in $x$-space, the geometric means of the three components must be rescaled so they sum to unity (by dividing each value by the sum of the three values). Because the distribution in $x$-space is geometrically equivalent to that in Sneed \& Folk ternary space, the point described by the geometric means of $x_{1}, x_{2}$ and $x_{3}$ is equivalent to the geometric mean of the original data distributed on the Sneed \& Folk diagram (Fig. 4).

The inverse transformation back into Sneed \& Folk ternary space is given in Table 1. There is no means of recovering the absolute size of each axis because this information has been lost by the conversion to ratios. However, if one axis is assumed, the others may be defined relative to it (and the particle 
will always plot in the same place on the Sneed \& Folk diagram). If a value for $a$ is assumed, $b=a\left(1-x_{2}\right)$, and $c=a x_{1}$.

\section{CONFIDENCE REGIONS FOR THE POPULATION MEAN PARTICLE SHAPE}

Once the mean shape of a sample has been defined it is possible to derive the confidence region for the mean shape of the population. The confidence region is an area on the ternary diagram within which the population mean lies with a given confidence, and is the multivariate equivalent of the confidence interval. Plotting of the confidence region enables the comparison of samples. The confidence region can be derived both theoretically, using parametric statistics, or computationally, using the statistical technique of bootstrapping. Both approaches require the data to be transformed initially into ternary $x$ space.

\section{Theoretical derivation of confidence regions}

The theoretical method of deriving confidence limits uses the properties of the additive logistic normal distribution (Aitchison, 1986), and is described in detail by Weltje (2002). The method is briefly summarised here.

The calculation of confidence regions by theoretical methods is based on the assumption that the population from which the data are drawn is normally distributed. In the case of ternary data, this assumption cannot hold because values, $v$, are constrained within the interval $\{0<v<1\}$, while the normal distribution can take any value, $v$, within the interval $\{-\infty<v<\infty\}$. This constraint is removed by the application of the log-ratio transformation, which 
converts the ternary $x$-space data into Cartesian coordinates, referred to as $y$ (or log-ratio) space:

$$
y_{i}=\log \left(\frac{x_{i}}{x_{3}}\right), \text { where } i=1,2
$$

so that (by substitution from Table 1 and simplification):

$y_{1}=\log \left(\frac{c}{b-c}\right)$, and: $y_{2}=\log \left(\frac{a-b}{b-c}\right)$

The central tendency of the sample may be characterised by the arithmetic mean of the data in $y$-space, which is equivalent to the geometric mean of the data in $x$-space calculated using Eq. (1).

A problem with the use of log-ratios is that they can produce indeterminate results if the lengths of two or more of the axes of a particle are identical. This may be overcome by adjusting the axes lengths slightly, which is justified on the basis that it is unlikely that two axes are exactly the same length. It is most likely that they apparently have the same length due to limitations in measurement precision. An appropriate adjustment is by the measurement precision (perhaps $\pm 1 \mathrm{~mm}$ if dealing with pebbles).

Log-ratios have the advantage that they are amenable to those parametric statistical methods based on the normal distribution, being able to take any value, $v$, within the interval $\{-\infty<v<\infty\}$. Log-ratios can be tested for bivariate normality with relative ease, and since the generation of valid confidence regions is contingent on the bivariate normality of $\left(y_{1}, y_{2}\right)$, this should be tested for each sample using one of the numerous appropriate tests.

Samples that are bivariate normal after log-ratio transformation follow the additive logistic normal distribution (Aitchison, 1986). If this is the case, the 
properties of this distribution can be used to construct confidence regions.

Confidence regions for the population mean are constructed using the multivariate equivalent of Student's $t$-test, Hotelling's $T^{2}$. In $y$-space, confidence regions are elliptical and centred on the sample mean; the lengths of the principal axes are controlled by the selected confidence level and the sample size.

For a significance level of $\alpha$, the boundary of the confidence region for the population mean is defined by:

$h_{\text {mean }}=[\bar{Y}-Y]^{\prime} S^{-1}[\bar{Y}-Y]=\frac{m(n-1)}{n(n-m)} F_{\left(1-\alpha ; d f_{1} ; d f_{2}\right)}$

where $\bar{Y}$ is a column vector of sample means, $Y$ is the specified column vector of population means, $S^{-1}$ is the inverse of the sample covariance matrix, $m$ is the number of variables $(=2), n$ is the sample size, and ' signifies transpose. $F_{\left(1-\alpha ; d f_{1} ; d f_{2}\right)}$ signifies the critical value of the $F$-statistic for confidence level $(1-\alpha)$ and degrees of freedom $d f_{1}=m$ and $d f_{2}=(n-m)$. A similar boundary can be drawn for the population, such that the region is expected to contain 100(1- $\alpha)$ percent of the observations drawn from the population:

$h_{\text {pop }}=[\bar{Y}-Y]^{\prime} S^{-1}[\bar{Y}-Y]=\frac{m(n-1)(n+1)}{n(n-m)} F_{\left(1-\alpha ; d f_{1} ; d f_{2}\right)}$

The solution to these equations is enabled by a rotation and translation into what is here referred to as $g$-space, such that the sample mean is at the origin and the principal axes of the ellipse are parallel to the coordinate axes. This ellipse is then given by: 
$\left(\frac{g_{1}}{w_{1} \sqrt{h}}\right)^{2}+\left(\frac{g_{2}}{w_{2} \sqrt{h}}\right)^{2}=1$

where $w_{1}{ }^{2}$ and $w_{2}^{2}$ are the eigenvalues of the sample covariance matrix in $y$ space and $h$ is $h_{\text {mean }}$ for the confidence region for the population mean and $h_{p o p}$ for the confidence region of the population. The $p$ boundary points of the confidence ellipse in $g$-space (in polar coordinates) are given by:

$\left\{\begin{array}{l}g_{1}=w_{1} \sqrt{h} \cos \beta \\ g_{2}=w_{2} \sqrt{h} \sin \beta\end{array}\right.$,

where $\beta=(2 i \pi / p)$ for $i=1, \ldots, p$.

The boundary points may be transferred back into $y$-space by rotation (multiplication by the matrix of sample eigenvectors) and translation (addition of $\bar{Y}$, the vector of sample means). The inverse log-ratio transformation is used to convert the points in $y$-space back into $x$ - (ternary compositional) space:

$$
x_{i}=\frac{z_{i}}{\sum_{i=1}^{3} z_{i}},
$$

where

$$
z_{i}=\left\{\begin{array}{c}
e^{y_{i}} \text { for } \quad i=1,2 \\
1 \text { for } i=3
\end{array}\right.
$$

Fig. 5 illustrates the shape of the theoretically-derived confidence region for one sample in $g$-space, $y$-space and $x$-space.

\section{Computational (bootstrap) derivation of confidence regions}

An alternative method of calculating confidence regions for the population mean uses a bootstrapping approach. This statistical technique uses the 
sample as a surrogate for the population. It can be shown that the statistical properties of repeated resamples of the sample vary in the same way as repeated resamples of the population (Efron, 1979).

The procedure to produce a bootstrap confidence region for the mean particle shape of the population based on a sample of size $n$ particles is:

1. Randomly draw $n$ particles, returning each particle to the original sample before drawing the next. Because each grain is replaced after selection, the bootstrap resample may contain any particular particle from the original sample zero or more times.

2. Repeat (1) $B$ times (where $B$ is many thousands).

3. Calculate the mean particle shape for each bootstrap resample using Equation (1) and plot on a Sneed \& Folk diagram.

4. Use the resulting point cloud to estimate the confidence region for the population mean shape.

The final step uses a convex hull peeling algorithm, similar to that employed by Ringrose \& Benn (1997). A convex hull is the line around a series of points that a stretched elastic band would take. Using this method, the distribution of bootstrap resample means on the Sneed \& Folk diagram may be used to generate approximate isolines of equal confidence for the population mean particle shape. By definition, at a particular significance level $\alpha$, the proportion of points that lie within the confidence region is $100(1-\alpha) \%$. To derive an estimate of a particular confidence region, convex hulls may be repeatedly peeled off from the cloud of data points until $100(1-\alpha) \%$ of the original points remain. 
This process is less reliable for the outermost convex hulls because they are sensitive to anomalous outliers (Ringrose and Benn, 1997). However, if a large enough number of bootstrap resamples are used (e.g. $B=10000)$, the confidence regions are stable for all routinely used confidence levels. Fig. 6 illustrates the bootstrap-derived confidence region for the same sample used in Fig. 4.

\section{VALIDATION OF CONFIDENCE REGIONS}

\section{Validation dataset and approach}

In addition to their use in calculating confidence regions, bootstrap methods were used to validate both the theoretically- and the computationally-derived confidence regions. To do so we employed 169 samples that together are representative of a wide range of naturally-occurring particle shapes. The samples, each of 50 clasts, were obtained from a variety of sedimentary environments, including ice-marginal moraines, river bars and channels, supraglacial sediments and slope deposits, all of which were located within glaciated or glacierized landscapes (Iceland, Svalbard and upland Britain). Across the samples, the minimum particle size varied between 7 and $20 \mathrm{~mm}$, and the maximum between 27 and $85 \mathrm{~mm}$ (as characterised by the $b$-axis measured with a ruler to the nearest millimeter).

\section{Validation of theoretically-derived confidence regions}

Because the mean of a sample drawn from a population should lie within the (1- $\alpha)$ confidence region $100(1-\alpha) \%$ of the time, it is possible to test the reliability of the theoretically-derived confidence regions by repeatedly 
resampling the sample ( $R$ times) and testing whether the resampled mean lies within the defined confidence region. The confidence regions may be considered reliable if they contain approximately the correct proportion of the bootstrap means. This procedure is illustrated schematically in Fig. 7A, and was repeated for each of the 169 validation samples.

The determination of whether the bootstrap means lie within the theoreticallyderived confidence region is facilitated by their transformation into $g$-space and the use of Equation (7) (which represents the confidence ellipse in $g$ space). Each mean shape $\left(g_{1}, g_{2}\right)$ is substituted into the equation; solutions $>1$ lie outside the confidence ellipse, and solutions $<1$ lie within it.

Use of the theoretical approach to derive confidence regions assumes that the sample is bivariate normal in $y$-space. For the 169 validation clast samples, the Mardia (1970) test of skewness and kurtosis indicated that the null hypothesis of bivariate normality was rejected in $57 \%$ of cases $(\alpha=0.05)$. However, the use of parametric techniques often results in only small errors when the assumption of normality is breached (Morrison, 2005 p.8).

For the sample presented previously, Fig. 8 shows the $g$-space $95 \%$ confidence region and 10000 bootstrap mean particle shapes. Although this sample is not bivariate normally distributed, $96.6 \%$ of the bootstrap means lie within the theoretically-derived confidence region, indicating that it does provide a reasonable estimate of the true confidence region. The performance of the confidence regions is reported in Table 2 for the 169 validation samples, and shows that the theoretically-derived confidence regions tend to slightly exaggerate the true confidence regions. 


\section{Validation of computationally-derived confidence regions}

The approach used to validate the computationally-derived confidence regions is illustrated schematically in Fig. 7B, and may be considered as the inverse of that used to validate the theoretical confidence regions. Multiple $(R)$ samples are drawn from a population and computational confidence regions calculated for each (using $B$ bootstrap resamples). The frequency with which the population mean lies within the calculated confidence regions is then determined. If the confidence regions are reliable, the population mean should be contained within approximately $100(1-\alpha) \%$ of them. Because the population is not known, this test can be simulated using a sample in lieu of the population.

This procedure was undertaken with $R=1000$ repeats and $n=50$ particles for each of the 169 validation samples. Confidence regions were calculated with $B=1000,5000,10000,50000$ and 100000 bootstrap resamples, and $\alpha=$ $0.05,0.01$ and 0.001 . The performance of the confidence regions is reported in Table 3 for each permutation of $B$ and $\alpha$. Unlike the theoretically-derived confidence regions, those derived computationally are slightly different each time they are calculated, so the number of bootstrap resamples $(B)$ must be sufficiently large to minimise this effect. The percentage of samples for which the population mean lies within the confidence region appears to stabilise by $B=10000$, indicating that additional resamples are unlikely to be necessary. However, in contrast to the theoretically-derived confidence regions, the computational method appears to slightly underestimate the true size of the confidence regions. 


\section{COMPARISON OF THEORETICALLY- AND COMPUTATIONALLY- DERIVED CONFIDENCE REGIONS}

The use of the theoretically-derived confidence limits has some advantages over the computational approach. Most importantly, because the equation of the confidence ellipse (in g-space) is known, it is easy to compare two samples to determine whether the confidence ellipses overlap. Similarly, it is possible to calculate the $p$-value (observed significance level) for rejection of the null hypothesis that two samples have the same mean shape.

Additionally, computationally-derived confidence limits have two disadvantages. The first is that they are slightly different each time they are calculated as a result of random variations in the resampling procedure (although it has been demonstrated that this effect is limited if a large number of resamples are made). Second, the convex-hull peeling algorithm always tends to make the confidence region more elliptical in $x$-space. This may not truly represent the shape of the confidence region in a space that is triangular. Although unlikely for particle shape data, the true confidence region for some types of compositional data may be 'banana' shaped (Weltje, 2002), a configuration that the convex-hull peeling algorithm cannot replicate.

Theoretically-derived confidence limits also have two important disadvantages. The first, that deviation from $y$-space bivariate normality results in inaccuracies in the size and shape of the confidence regions, has already been discussed. The second is that the confidence regions are very sensitive to particles lying close to the edges of the ternary diagram in Sneed \& Folk and $x$-space. This means that the approach is sensitive to choices 
made about the adjustments to avoid indeterminate results. The effect of this is illustrated in Fig. 9 for the same sample used in Fig. 4. In the original data, a single particle lies on the right-hand edge of the Sneed \& Folk diagram (a-axis $=22 \mathrm{~mm} ; b$-axis $=c$-axis $=15 \mathrm{~mm})$. To calculate confidence regions the data are adjusted to make the $c$-axis slightly smaller than the $b$-axis. If a very small adjustment is made $(0.001 \mathrm{~mm})$, the confidence region is substantially stretched and enlarged compared with an adjustment in the order of the measurement precision $(1 \mathrm{~mm})$. The region is stretched both towards the point, and in the opposite direction (towards the bottom-left; Fig. 9A). This is because the confidence regions are predicated on the normality of the data, and as the normal distribution is symmetrical an outlier at one end of the distribution results in a stretching of the confidence region in the opposite direction too. Robust confidence limits should not be substantially influenced by individual outliers; hence a very small adjustment is inappropriate. Removal of the point from the data (Fig. 9C) results in only a small change in the confidence regions compared with the adjustment by $1 \mathrm{~mm}$ (Fig. 9B). This analysis suggests that the use of an adjustment in the order of the measurement precision is appropriate, and its use will not result in substantial distortion of the confidence regions. As an example, in the extreme case where $a=b=c$, the perturbation applied would be $a^{*}=a+d, b^{*}=b, c^{*}=c-$ $d$, where $d$ is equal to the measurement precision (perhaps $1 \mathrm{~mm}$ when measuring pebbles with a ruler). A variety of other adjustments to avoid indeterminate results are possible, and the precise method chosen is unlikely to be important provided that it moves the particle sufficiently away from the edges of the ternary diagram. 


\section{STATISTICAL TESTS ON THE MEAN}

The graphical representation of mean particle shape and its confidence region provides a powerful method for summarising and presenting data. It also provides an indication of whether samples are likely to have been drawn from the same population. Where there is no overlap between the confidence regions of the population means for two samples, we can reject the null hypothesis that they are drawn from the same population. However, the converse is not true: where the confidence regions do overlap, it does not (necessarily) imply that we are unable to reject the null hypothesis.

The analysis presented above provides some assurance that theoreticallyderived confidence regions are robust. It is therefore appropriate to apply conventional multivariate tests on the null hypothesis that two samples are drawn from populations with the same mean. As for the calculation of confidence regions, shape data must first be transformed into $x$-space, and then into bivariate $y$-space via log-ratio transformation.

The standard test is Hotelling's $T^{2}$ test for two multivariate independent samples (Morrison, 2005), the multivariate extension of Student's $t$-test. The two sample Hotelling's $T^{2}$ test statistic is given by

$T^{2}=\frac{n_{1} n_{2}}{n_{1}+n_{2}}\left[\bar{Y}_{1}-\bar{Y}_{2}\right]^{\prime} S^{-1}\left[\bar{Y}_{1}-\bar{Y}_{2}\right]$

where $\bar{Y}_{x}$ is a column vector of means for sample $Y_{x}$ of size $n_{x}$. The test assumes that the sample covariance matrices are equal, and uses the pooled covariance matrix of $Y_{1}$ and $Y_{2}$,

$S_{p}=\frac{\left(n_{1}-1\right) S_{1}+\left(n_{2}-1\right) S_{2}}{\left(n_{1}+n_{2}-2\right) m}$ 
where $S_{x}$ is the covariance matrix for sample $Y_{x}$ and $m$ is the number of variables (=2).

The $F$ statistic is then

$F=\frac{n_{1}+n_{2}-m-1}{\left(n_{1}+n_{2}-2\right) m} T^{2} \sim F\left(m, n_{1}+n_{2}-m-\alpha\right)$

If $F>F_{\text {crit }}$ then the null hypothesis is rejected.

As the test uses the pooled covariance matrix, it assumes that the sample covariance matrices are equal (Rencher, 2002). If this is not true, it may result in type I errors (null hypothesis is incorrectly rejected). Where sample sizes are equal and large, the $T^{2}$ test is robust (Ito and Schull, 1964). In other cases it is appropriate to test this assumption using Box's M-test (Rencher, 2002).

\section{EXAMPLE APPLICATION}

Graham \& Hambrey (2009) examined the genesis of a variety of Younger Dryas Stadial glacial landforms in upper Ennerdale, English Lake District. Within the moraine systems in the valley they identified two key lithofacies: muddy sandy-gravel and clast-rich sandy diamicton. Both were interpreted as being composed of predominantly subglacially transported material. This interpretation was on the basis of a predominance of subangular and subrounded clasts, low RA index (the proportion of angular and very angular clasts), low $\mathrm{C}_{40}$ index (the proportion of clasts with a c:a axial ratio $\leq 0.4$ ), presence of a small number of striated clasts, and poorly-sorted texture (for the diamicton), all of which are characteristic of subglacially transported sediment (Benn and Ballantyne, 1994; Bennett et al., 1997; Boulton, 1978; Kirkbride, 1995). For comparison, they collected control samples from the 
contemporary stream channel running through the moraines, and a talus slope located on the valley side above the moraines.

Two clast shape samples from each of the moraine and control facies are presented in Fig. 10. A key question is whether these data support the interpretation of the diamicton and gravel facies made by Graham \& Hambrey (2009). If these samples contain a high proportion of passively transported sediment, it might be expected that their shape would be similar to the talus control sample. If they had been substantially modified by fluvial activity, they might be expected to be similar to the fluvial control sample. The answer to the question is not immediately obvious because there is substantial overlap in the distributions of the clast samples. The question may be restated in a statistical sense as a test of the null hypothesis that the gravel, diamicton, fluvial and talus samples were drawn from a population with the same mean. In this example, a significance level of $\alpha=0.05$ is considered an appropriate balance between type I and type II errors.

Fig. 11 shows the $95 \%$ confidence regions (derived both theoretically and computationally) for the clast samples presented in Fig. 10. As expected the confidence regions for the two fluvial sample means have substantial overlap, giving confidence that these samples were drawn from the same population. Hotelling's $T^{2}$ test confirms this: it is not possible to reject the null hypothesis that the two samples have the same mean shape $(p=0.80)$. The same is true of the two talus samples $(p=0.99)$.

The means of the two diamicton samples are very similar, and there is substantial overlap between the $95 \%$ confidence regions. Once again, it is not 
possible to reject the null hypothesis that the two samples have the same mean shape $(p=0.97)$. This provides strong support for these samples having the same origin.

The means of the two gravel samples appear substantially different, but their confidence regions overlap. Clast shape provides some evidence that the two samples may have different histories, but the null hypothesis that they come from the same population cannot be rejected $(p=0.06)$. Other evidence (e.g. clast roundness; matrix grain-size distribution) supports the conclusion that the samples do in fact have the same origin.

The confidence regions of the diamicton and gravel samples show considerable overlap. Pooling the two diamicton samples and the two gravel samples allows a test of the null hypothesis that the two pooled samples have the same mean shape. The null hypothesis cannot be rejected $(p=0.30)$, lending support to the interpretation that these samples have the same (or similar) origins. Both the pooled gravel and diamicton samples are significantly different from the pooled fluvial and talus control samples $(p<$ $0.001)$.

Although this analysis does not enable direct interpretation of the transport history of the diamicton and gravel facies, it provides support for the inferences that they have a similar origin and that they do not include a large proportion of passively transported rockfall material. Other evidence (the most compelling of which is the presence of striated clasts) must be used to conclude that the gravel and diamicton facies are most likely to have a subglacial origin. 
This example illustrates how the statistical approach presented here - using both graphical representation of confidence regions and formal statistical tests - adds to the available evidence available for the interpretation of sedimentary facies. It is unlikely that inferential testing of particle shape samples will be used as the sole means of differentiating facies, but it adds to the suite of tools available when making sedimentological interpretations.

\section{CONCLUSION}

Although particle shape data has the potential to contribute valuable information to assist with the interpretation of a sediment body, its application has been inhibited by the absence of an accepted method for defining the ‘average' shape for a sample of particles. This paper has presented a new method for defining average shape, based on the Sneed \& Folk (1958) representation of the particle shape continuum. The definition is based on the geometric mean of the sample after normalization to transform the data into ternary compositional space ( $x$-space).

The transformation into ternary compositional space, and the definition of the sample mean particle shape that follows from it, enables the derivation of confidence regions for the population mean particle shape and the application of statistical tests on the mean. These confidence regions may be defined theoretically under the assumption of bivariate normality (following log-ratio transformation), or computationally using the bootstrapping method and a convex-hull peeling algorithm.

For a diverse set of 169 test samples (each of 50 particles), both techniques produce generally consistent results, despite the assumption of bivariate 
normality being breached in $57 \%$ of cases. Validation tests indicate that the theoretical method tends to exaggerate the true confidence regions very slightly and the computational method tends to underestimate them slightly. The generation of reliable confidence regions using the computational approach requires a large (c.10 000) number of bootstrap resamples.

To avoid indeterminate results during the calculation of theoretically-derived confidence regions it is necessary to avoid the situation where a particle lies along one of the axes of the Sneed \& Folk diagram (as a result of two or three particle axes having the same length). This may be achieved by adjusting the lengths of the axes slightly (such that $a>b>c$ ). Since the shape and size of theoretically-derived confidence regions are sensitive to particles lying very close to the edges of the Sneed \& Folk diagram, it is recommended that the adjustment should be large enough to avoid substantial distortion of the confidence regions. Adjustment by an amount reflecting the precision with which measurements may be made is sufficient to avoid this effect.

The new definition of mean particle shape permits the application of inferential statistics to shape data for the first time, using the multivariate equivalent of Student's $t$-test, Hotelling's $T^{2}$. 


\section{COMPUTATIONAL DETAILS}

Calculations were undertaken using MATLAB®. Copies of the functions and sample data may be downloaded from the Loughborough University Physical Geography Resources Gateway (http://www.lboro.ac.uk/research/physgeog/).

\section{ACKNOWLEDGEMENTS}

We thank Mark Szegner for assistance with producing the figures, Steve Rice for internally reviewing the work, and Simon Blott for helpful discussions on the nature of particle shape and his review of an earlier version of the manuscript. Thanks also to Doug Benn, Nicholas J Cox, Bryn Hubbard, Gert Jan Weltje and three anonymous reviewers for their suggestions that have helped to improve the manuscript.

\section{REFERENCES}

Aitchison J. 1986. The Statistical Analysis of Compositional Data. Chapman \& Hall: London.

Benn DI. 2004. Clast morphology. In A Practical Guide to the Study of Glacial Sediments, Evans DJA, Benn DI (eds). Arnold: London, 78-92.

Benn DI, Ballantyne CK. 1992. Pebble shape (and size!): discussion. Journal of Sedimentary Research 62: 1147-1150.

Benn DI, Ballantyne CK. 1993. The description and representation of particle shape. Earth Surface Processes and Landforms 18: 665-672. DOI:

10.1002/esp.3290180709 
Benn DI, Ballantyne CK. 1994. Reconstructing the transport history of glacigenic sediments: a new approach based on the co-variance of clast form indices. Sedimentary Geology 91: 215-227. DOI: 10.1016/00370738(94)90130-9

Benn DI, Ballantyne CK. 1995. Grain-shape indices and isometric graphs: discussion. Journal of Sedimentary Research 65: 719-721.

Bennett MR, Hambrey MJ, Huddart D. 1997. Modification of clast shape in High-Arctic glacial environments. Journal of Sedimentary Research 67: 550559.

Blott SJ, Pye K. 2008. Particle shape: a review and new methods of characterization and classification. Sedimentology 55: 31-63. DOI: 10.1111/j.1365-3091.2007.00892.x

Boulton GS. 1978. Boulder shapes and grain-size distributions of debris as indicators of transport paths through a glacier and till genesis. Sedimentology 25: 773-799. DOI: 10.1111/j.1365-3091.1978.tb00329.x

Church MA, McLean DG, Wolcott JF. 1987. River bed gravels: sampling and analysis. In Sediment Transport in Gravel-Bed Rivers, Thorne CR, Bathurst JC, Hey RW (eds). Wiley: Chichester; 43-79.

Dowdeswell JA, Hambrey M, Wu, R. 1985. A comparison of clast fabric and shape in Late Precambrian and modern glacigenic sediments. SEPM Journal of Sedimentary Petrology 55: 691-704. DOI: 10.1306/212F87BF-2B24-11D78648000102C1865D 
Efron B. 1979. Bootstrap methods: another look at the jackknife. The Annals of Statistics 7: 1-26. DOI: 10.1214/aos/1176344552

Evans DJA, Benn DI. 2004. A Practical Guide to the Study of Glacial Sediments. Arnold: London.

Folk RL. 1955. Student operator error in determination of roundness, sphericity, and grain size. Journal of Sedimentary Research 25: 297-301.

Graham DJ, Hambrey MJ. 2009. Sediments and landforms in an upland glaciated-valley landsystem: Upper Ennerdale, English Lake District. In Glacial Sedimentary Processes and Products, Hambrey MJ, Christoffersen P, Glasser NF, Hubbard B (eds). Blackwell Publishing: Oxford, UK; 235-256.

Graham DJ, Midgley NG. 2000. Graphical representation of particle shape using triangular diagrams: an Excel spreadsheet method. Earth Surface Processes and Landforms 25: 1473-1477.

Hofmann HJ. 1994. Grain-shape indices and isometric graphs. Journal of Sedimentary Research 64: 916-920.

Hofmann HJ. 1995. Grain-shape indices and isometric graphs: reply. Journal of Sedimentary Research 65: 721-723.

Howard JL. 1992. An evaluation of shape indices as palaeoenvironmental indicators using quartzite and metavolcanic clasts in Upper Cretaceous to Palaeogene beach, river and submarine fan conglomerates. Sedimentology 39: 471-486. DOI: 10.1111/j.1365-3091.1992.tb02128.x 
Howard JL. 1993. An evaluation of shape indices as palaeoenvironmental indicators using quartzite and metavolcanic clasts in Upper Cretaceous to Palaeogene beach, river and submarine fan conglomerates: reply.

Sedimentology 40: 1020-1021. DOI: 10.1111/j.1365-3091.1993.tb01374.x Illenberger WK. 1991. Pebble shape (and size!). Journal of Sedimentary Research 61: 756-767.

Illenberger WK. 1992a. Pebble shape (and size!): reply. Journal of Sedimentary Research 62: 538-540.

Illenberger WK. 1992b. Pebble shape (and size!): reply. Journal of Sedimentary Research 62: 1151-1155.

Ito K, Schull WJ. 1964. On the robustness of the $\mathrm{T}_{0}^{2}$ test in multivariate analysis of variance when variance-covariance matrices are not equal. Biometrika 51: 71-82.

Kirkbride MP. 1995. Processes of transportation. In Modern Glacial Environments: Processes, Dynamics and Sediments, Menzies J (ed). Butterworth-Heinemann: Oxford; 261-308.

Lukas S, Benn DI, Boston CM, Brook M, Coray S, Evans DJA, Graf A, Kellerer-Pirklbauer A, Kirkbride M, Krabbendam M, Lovell H, Machiedo M, Mills SC, Nye K, Reinardy BTI, Ross FH, Sifner M. 2013. Clast shape analysis and clast transport paths in glacial environments: a critical review of methods and the role of lithology. Earth-Science Reviews 121: 96-116. DOI:

10.1016/j.earscirev.2013.02.005 
Mardia KV. 1970. Measures of multivariate skewness and kurtosis with applications. Biometrika 57: 519-530. DOI: 10.1093/biomet/57.3.519

Morrison DF. 2005. Multivariate Statistical Methods, Fourth Edition. Thomson: Belmont, CA.

Oakey RJ. 2002. The Use of Tracers to Determine Coarse-Bedload Transport in a Gravel-Bed River. Unpublished PhD thesis. University of Lancaster.

Oakey RJ, Green M, Carling PA, Lee MWE, Sear DA, Warburton J. 2005. Grain-shape analysis: a new method for determining representative particle shapes for populations of natural grains. Journal of Sedimentary Research 75: 1065-1073. DOI: 10.2110/jsr.2005.079

Rencher AC. 2002. Methods of Multivariate Analysis, Second Edition. Wiley: New York.

Ringrose TJ, Benn DI. 1997. Confidence regions for fabric shape diagrams. Journal of Structural Geology 19: 1527-1536. DOI: 10.1016/S01918141(97)00077-1

Sneed ED, Folk RL. 1958. Pebbles in the lower Colorado River, Texas: a study in particle morphogenesis. Journal of Geology 66: 114-150.

Tarriño, A. 2015. A new methodology and classification system for describing three-dimensional particle formats: application to clastic lithic products of archaeological and geological origin. Archaeometry 57: 928-948. DOI: 10.1111/arcm. 12142 
Weltje GJ. 2002. Quantitative analysis of detrital modes: statistically rigorous confidence regions in ternary diagrams and their use in sedimentary petrology. Earth-Science Reviews 57: 211-253. DOI: 10.1016/S00128252(01)00076-9

Woronow A. 1992. Pebble shape (and size!): discussion. Journal of Sedimentary Research 62: 536-537.

Zingg T. 1935. Beitrag zur Schotteranalyse. Schweizerische Mineralogische und Petrographische Mitteilungen 15: 39-140. DOI: 10.3929/ETHZ-A000103455 
Table 1. The transformation between the Sneed \& Folk and compositional ternary diagrams

Sneed \& Folk Compositional Inverse transformation

scaling scaling ( $x$-space) (compositional to

Sneed \& Folk scaling)

\begin{tabular}{llll}
\hline Axis 1 (left) & $c / a$ & $x_{1}=c / a$ & $c / a=x_{1}$ \\
Axis 2 (right) & $b / a$ & $x_{2}=(a-b) / a$ & $b / a=1-x_{2}$ \\
Axis 3 (bottom) & $(a-b) /(a-c)$ & $x_{3}=(b-c) / a$ & $(a-b) /(a-c)=x_{2} /\left(1-x_{1}\right)$ \\
\hline
\end{tabular}


Table 2. Percentage of bootstrap means that lie within the theoreticallyderived confidence region (for $B=10000$ ). See text for explanation.

\begin{tabular}{ll}
\hline Significance level $(\alpha)$ & Percent (standard deviation) \\
\hline 0.001 & $99.97(0.02)$ \\
0.01 & $99.49(0.07)$ \\
0.05 & $96.40(0.17)$ \\
\hline
\end{tabular}


Table 3. Percentage of samples with population mean inside the bootstrap confidence region. See text for explanation.

\begin{tabular}{llllll}
\hline $\begin{array}{l}\text { Significance } \\
\text { level }(\alpha)\end{array}$ & $\begin{array}{l}B=1000 \\
\text { Percent (sd) }\end{array}$ & $\begin{array}{l}B=5000 \\
\text { Percent (sd) }\end{array}$ & $\begin{array}{l}B=10000 \\
\text { Percent (sd) }\end{array}$ & $\begin{array}{l}B=50000 \\
\text { Percent (sd) }\end{array}$ & $\begin{array}{l}B=100000 \\
\text { Percent } \\
(\mathrm{sd})\end{array}$ \\
\hline 0.001 & $97.95(0.48)$ & $99.31(0.27)$ & $99.52(0.24)$ & $99.54(0.22)$ & $\begin{array}{l}99.58 \\
(0.20)\end{array}$ \\
0.01 & $97.80(0.50)$ & $97.99(0.49)$ & $97.96(0.46)$ & $98.07(0.47)$ & $\begin{array}{l}98.06 \\
(0.48)\end{array}$ \\
& & & & & 93.19 \\
0.05 & $92.30(0.88)$ & $93.02(0.84)$ & $93.20(0.86)$ & $93.21(0.87)$ & \begin{tabular}{l}
$9.89)$ \\
\hline
\end{tabular} \\
\hline
\end{tabular}


A

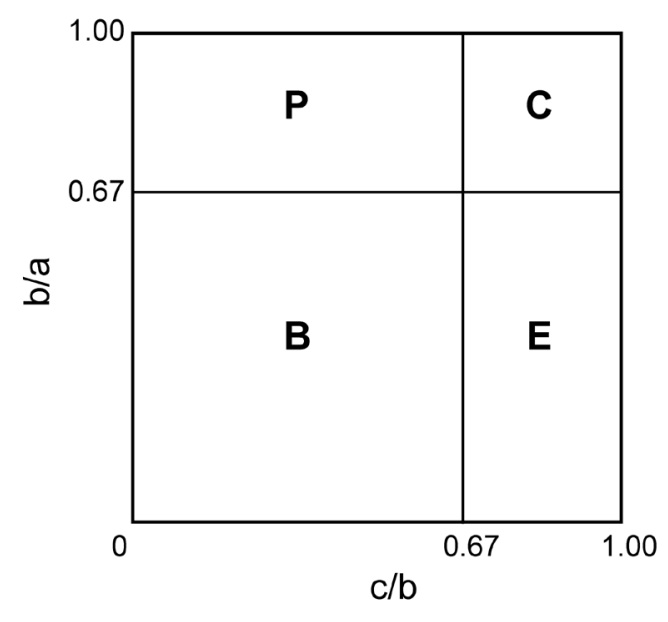

B

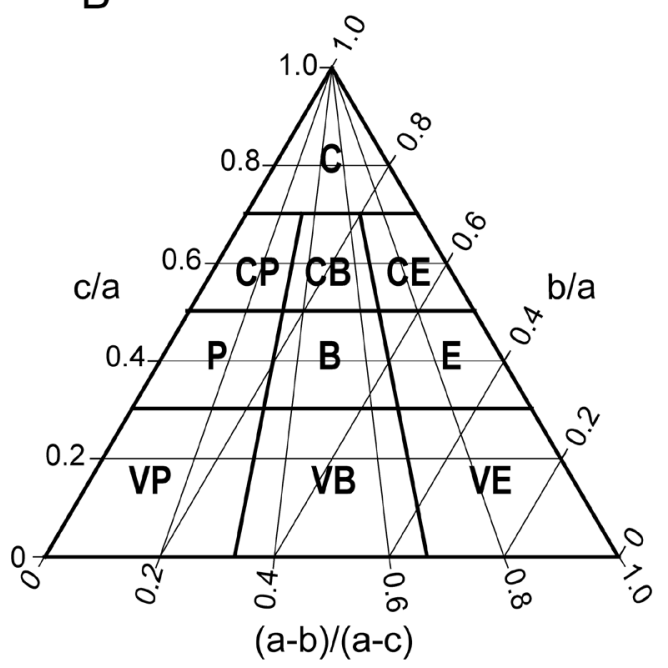

Fig. 1. Commonly used particle-shape diagrams. Textural descriptors of shape follow Sneed \& Folk (1958). C = compact (equant); $P$ = platy; $B=$ bladed; E = elongate; V = very. (A) The Zingg (1935) diagram. (B) The Sneed \& Folk (1958) diagram. 
A

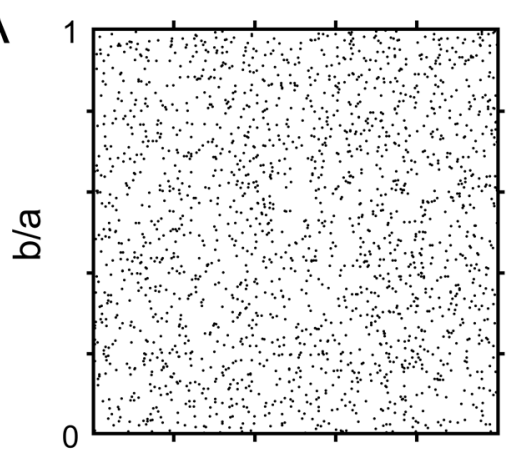

B

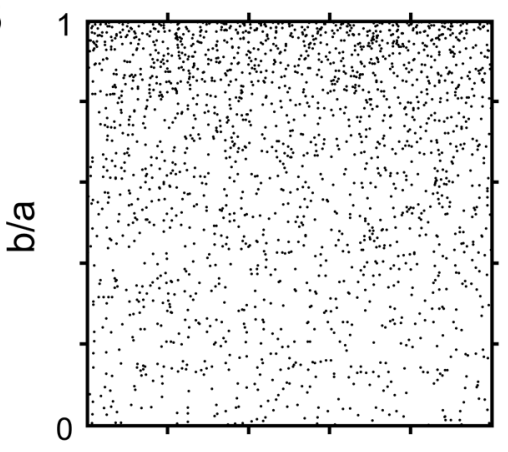

C

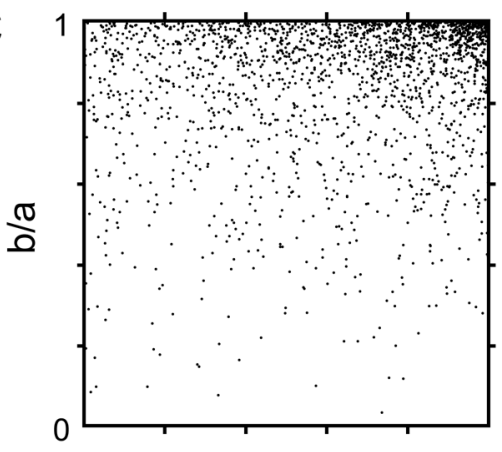

D

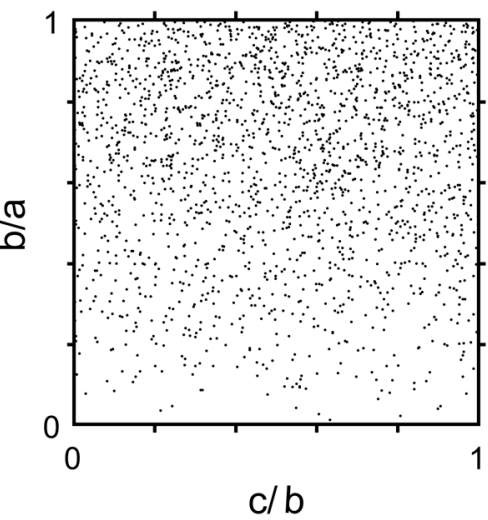

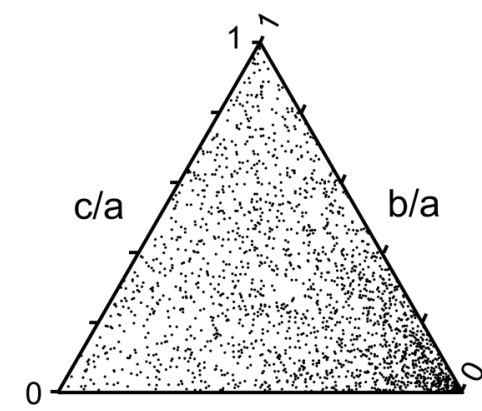
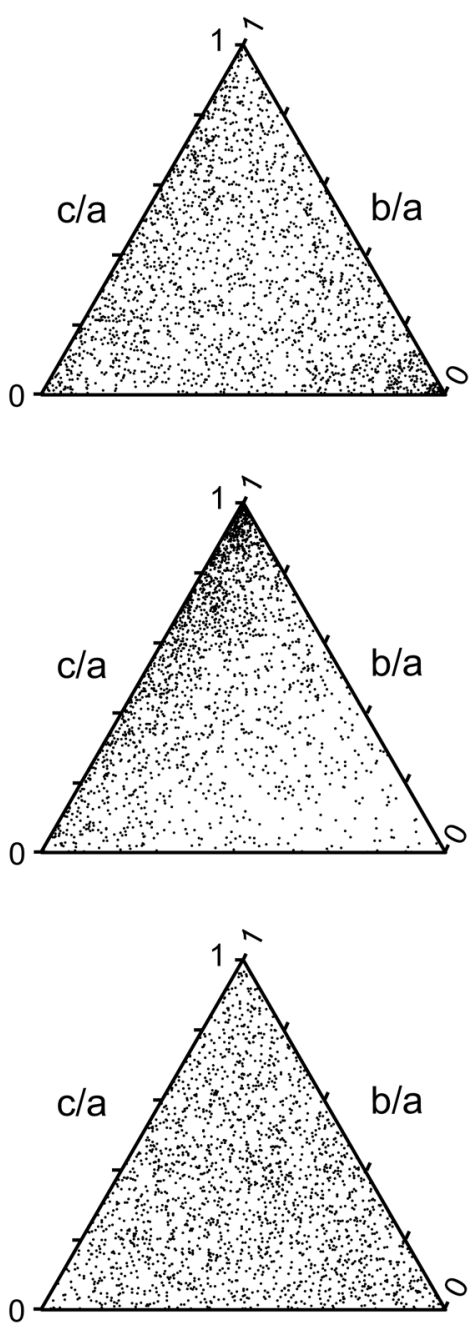

Fig. 2. The distribution of shapes on Zingg and Sneed \& Folk diagrams for 2000 computer-generated particles. Scaling as in Fig. 1. (A) The axes were drawn from a uniform distribution in the order $a, b, c$ such that: $0 \leq a \leq 1 ; 0 \leq b$ $\leq a ; 0 \leq c \leq b$. The distribution is even on the Zingg diagram, but uneven on 
the Sneed \& Folk diagram. This is the method proposed by Blott \& Pye (2008). (B) The axes were drawn from a uniform distribution in the order $b, c$, a such that: $0 \leq b \leq 1 ; 0 \leq c \leq b ; b \leq a \leq 1$. The distribution is uneven on both the Zingg and Sneed \& Folk diagrams. (C) The axes were drawn from a uniform distribution in the order $c, b$, a such that: $0 \leq c \leq 1 ; c \leq b \leq 1 ; b \leq a \leq 1$. The distribution is uneven on both the Zingg and Sneed \& Folk diagrams. (D) The three axes were independently drawn from the unit uniform distribution and sorted so that $a \geq b \geq c$. The distribution is uneven on the Zingg diagram, but even on the Sneed \& Folk diagram. 


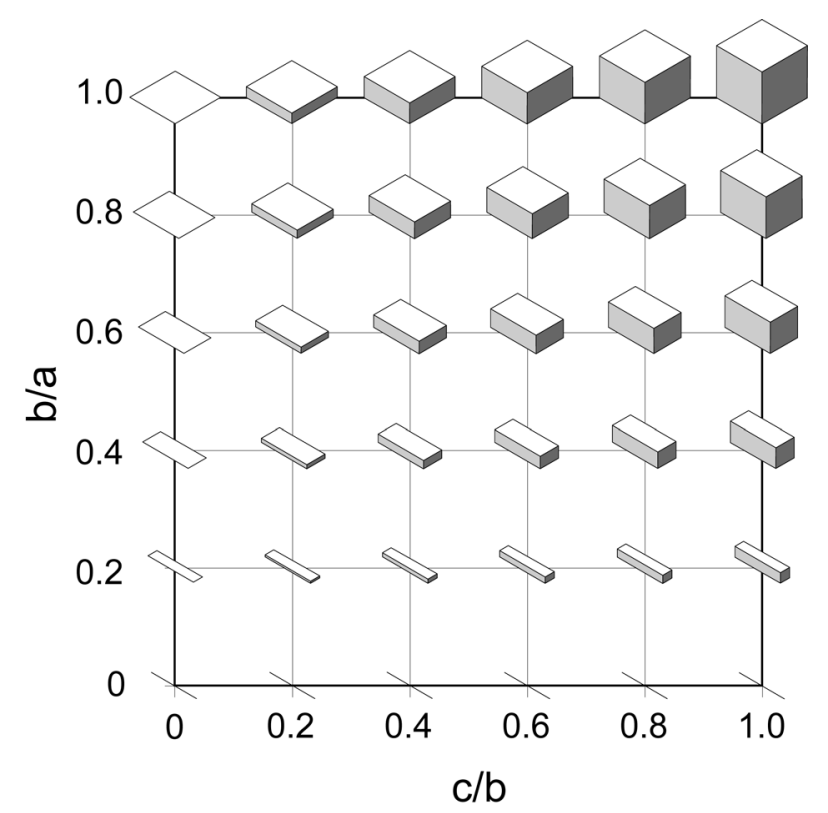

Fig. 3. The distribution of selected idealised shapes on the Zingg diagram.

Note that extreme rods plot along the entire length of the $x$-axis. Modified from Blott \& Pye (2008). 

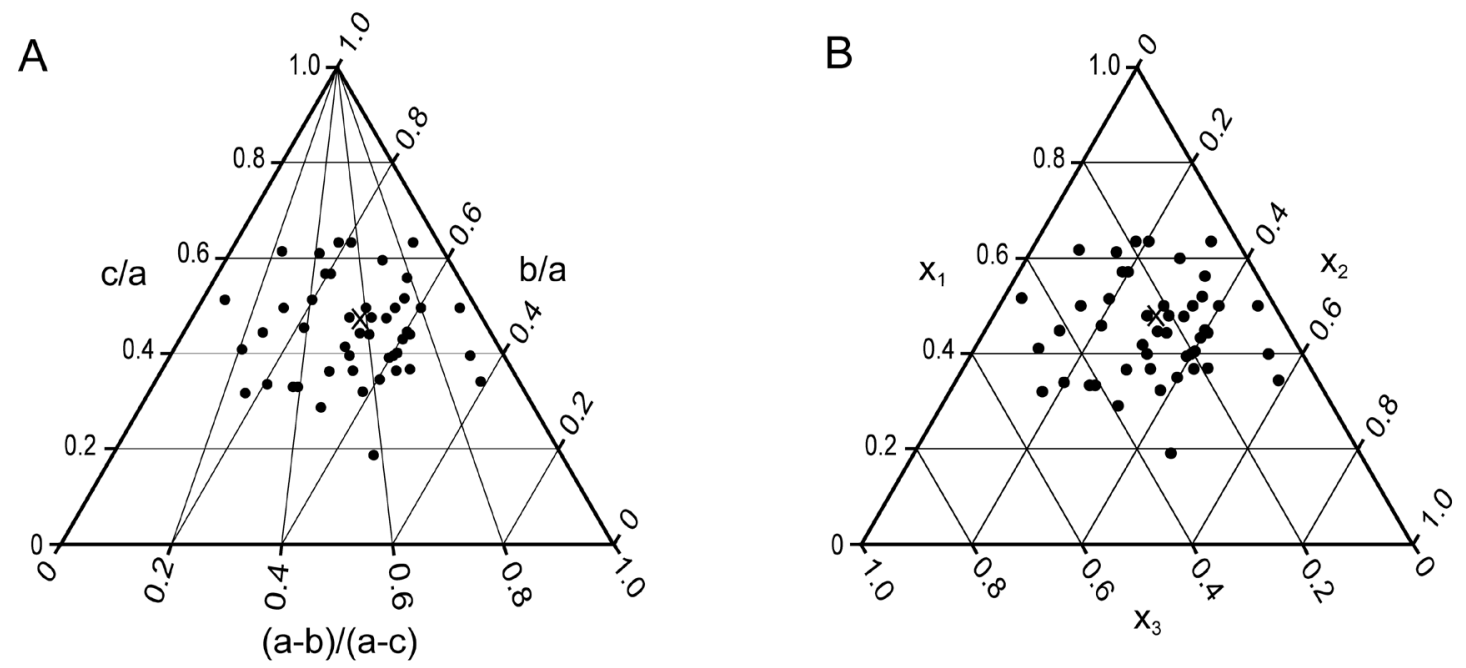

Fig. 4. Diagram showing the scaling of $(A)$ the Sneed \& Folk and $(B)$ compositional ternary diagrams. The cross marks the sample geometric mean shape. The data are from a moraine composed of sandy gravel in front of Austre Lovénbreen, Svalbard (Graham, 2002). 
A

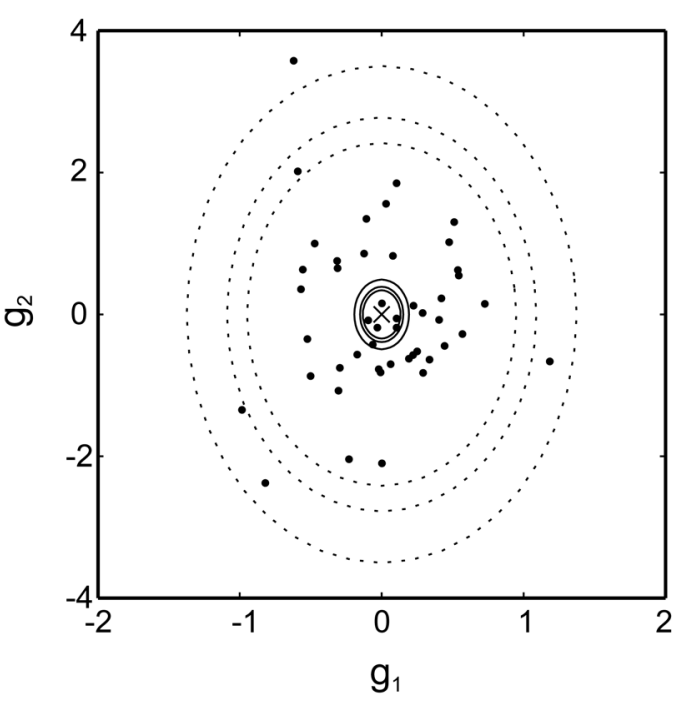

B

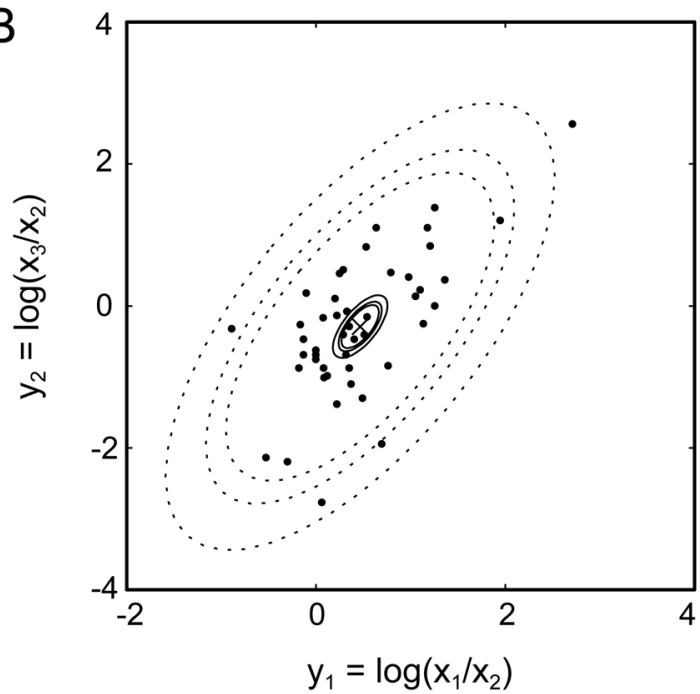

C

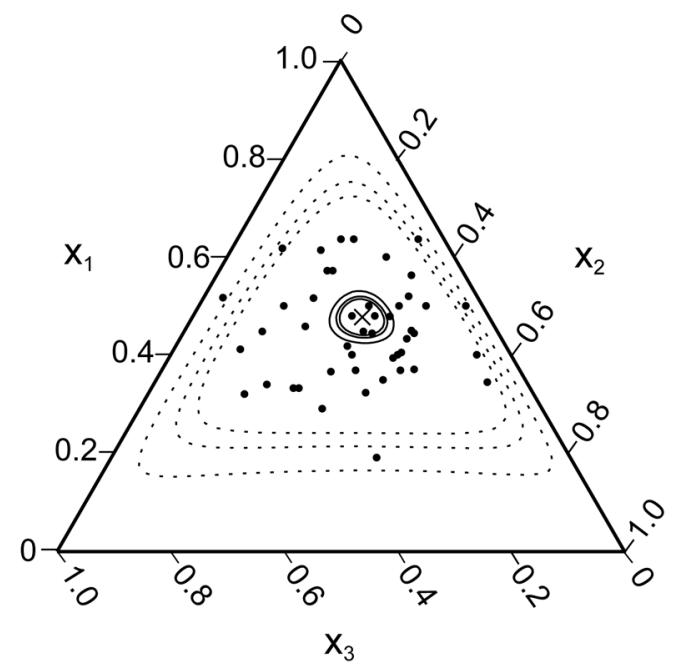


Fig. 5. Particle-shape data for the sample presented in Fig. 4 and theoretically-derived confidence region for the population mean (solid lines) and entire population (dashed lines) at the $90 \%, 95 \%$ and $99 \%$ confidence levels. The cross marks the sample geometric mean shape. (A) Confidence regions in g-space. (B) Confidence regions in $y$ - (log-ratio) space. (C) Confidence regions in $x$ - (ternary composition) space. The regions have the same shape on the Sneed \& Folk diagram. 


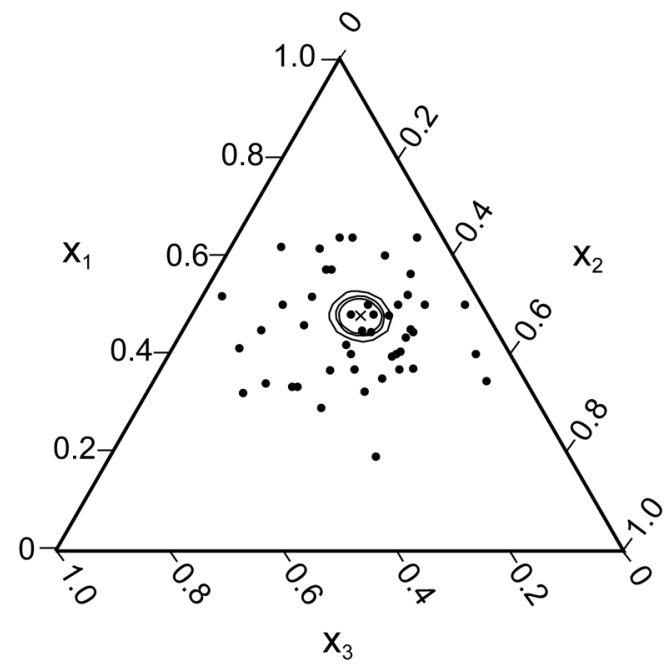

Fig. 6. Particle-shape data for the sample presented in Fig. 4 and computationally-derived confidence region for the population mean at the $90 \%, 95 \%$ and $99 \%$ confidence levels. The cross marks the sample geometric mean shape. Data are in $x$ - (ternary composition) space. The regions have the same shape on the Sneed \& Folk diagram. 


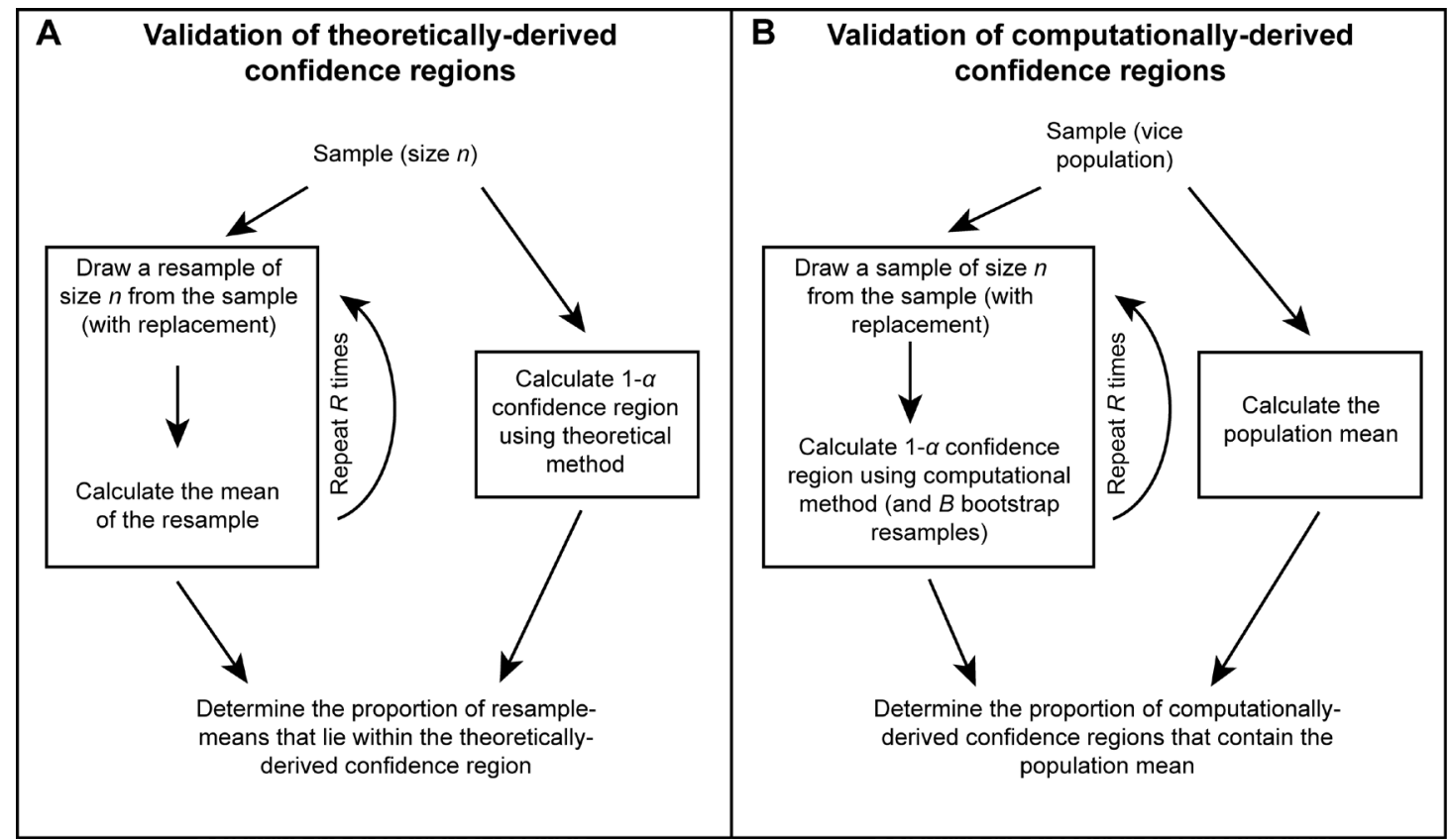

Fig. 7. Schematic representation of the validation procedure for (A) theoretically-derived confidence regions and (B) computationally-derived confidence regions. For further details, see text. 


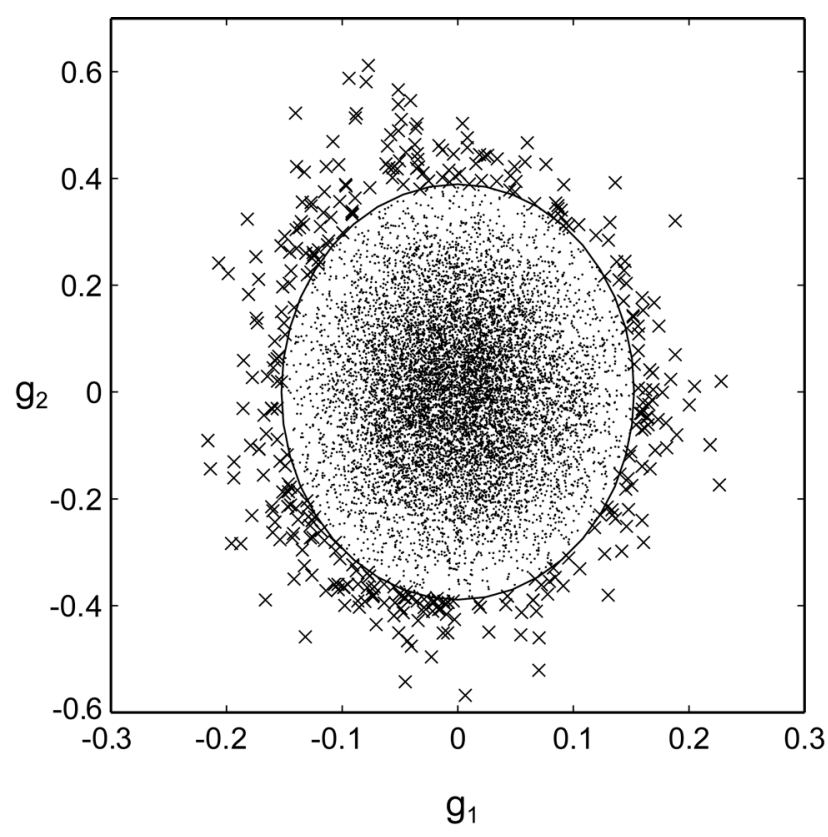

Fig. 8. The theoretically-derived $95 \%$ confidence region in $g$-space for the sample presented in Fig. 4. Superimposed are 10000 bootstrap estimates of the population mean. Dots represent the $96.6 \%$ of the bootstrap estimates that lie within the confidence region; crosses the $3.4 \%$ of estimates that lie outside. The crosses are not evenly distributed around the confidence ellipse because the sample is not bivariate normal. 

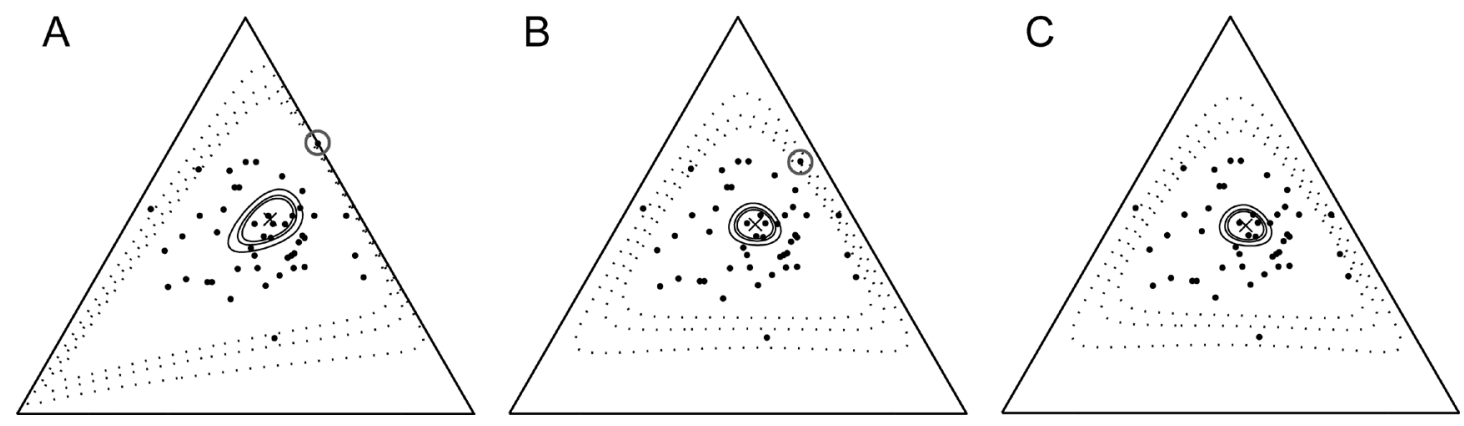

Fig. 9. The sensitivity of theoretically-defined confidence limits to a particle lying close to the edge of the Sneed \& Folk diagram (circled). Confidence regions for the population mean (solid lines) and entire population (dashed lines) are shown at the $90 \%, 95 \%$ and $99 \%$ levels. The cross marks the sample geometric mean shape. The sample is the same as that used in Fig. 4. (A) The $c$-axis of the marginal particle (circled) is reduced by $0.001 \mathrm{~mm}$, moving it just off the right-hand axis and enabling calculation of confidence regions without division-by-zero errors. The confidence regions are large and stretched-out across the diagram. (B) The $c$-axis of the particle is reduced by $1 \mathrm{~mm}$, equivalent to the measurement precision. The confidence regions are reduced in size. (C) The particle is removed. The size and shape of the confidence regions are very similar to those in (B). 

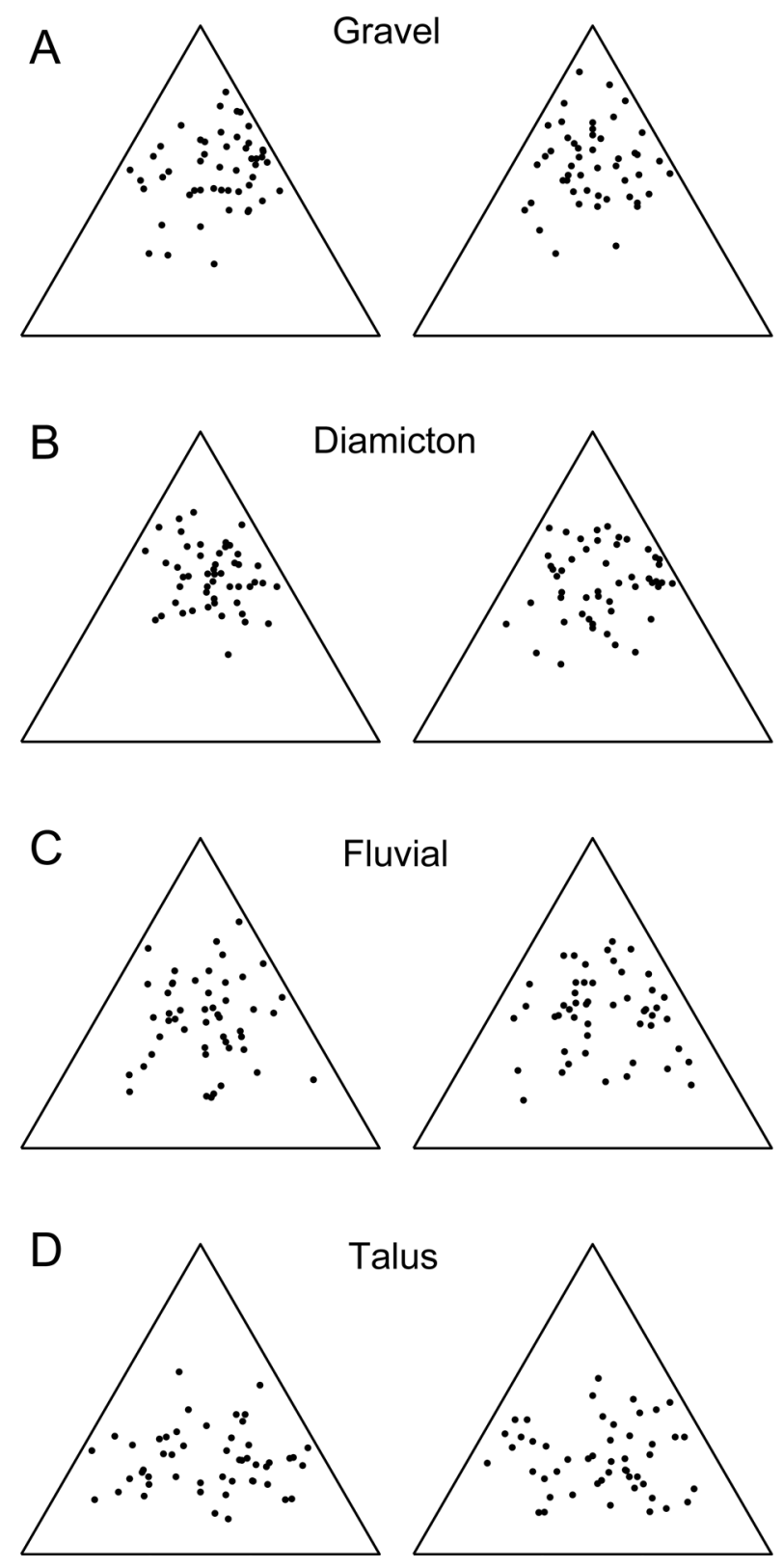

Fig. 10. Sneed \& Folk ternary diagrams showing clast shape data for within and around the moraines in Ennerdale, English Lake District (Graham and Hambrey, 2009). (A) Muddy sandy-gravel within the valley-side morainemound complex. (B) Clast-rich sandy diamicton within the valley-side moraine-mound complex. (C) Fluvial gravel from a modern channel close to the moraines. (D) Talus gravel from the valley side above the moraines. 


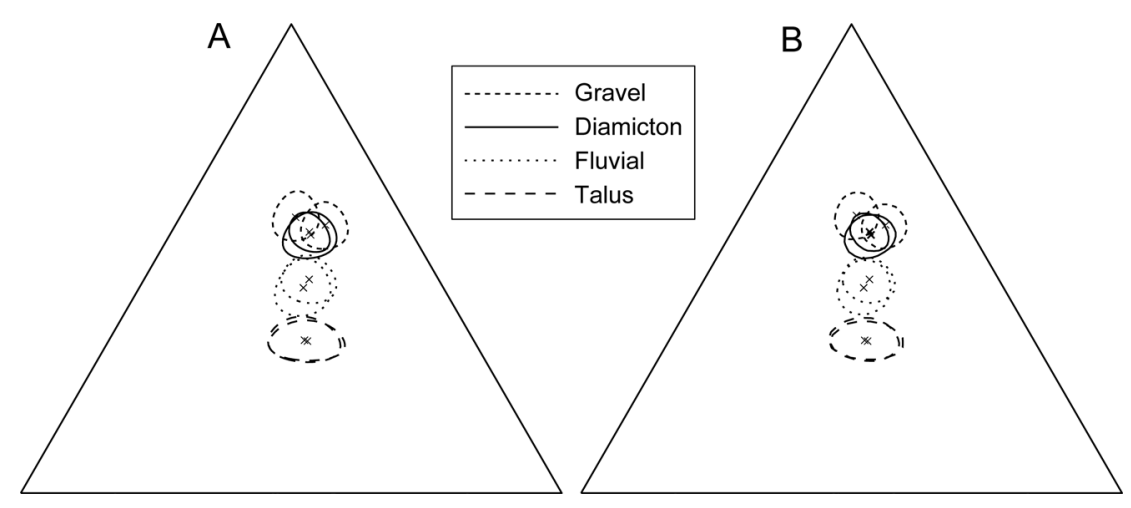

Fig. 11. Mean shape and $95 \%$ confidence regions for the population mean for the samples presented in Fig. 10. (A) Theoretically-derived confidence regions. (B) Computationally-derived confidence regions. 